\title{
Handover of patients: the challenges of COVID-19
}

\author{
Netanel Wasserteil ${ }^{1} \cdot$ Alona Bin Nun $\mathbb{D}^{1} \cdot$ Francis B. Mimouni $^{1,2} \cdot$ Yair Kasirer $^{1}$
}

Received: 6 July 2020 / Revised: 19 July 2020 / Accepted: 7 August 2020 / Published online: 21 August 2020

(c) Springer Nature America, Inc. 2020

A recent Cochrane review addressed the issue of handover style for insuring continuity of care in hospitalized patients [1]. Regardless of whether handover is at the bedside or in a meeting room, the Covid-19 pandemics have raised new challenges. Indeed, the Center for Diseases Control (CDC) recommends that at the workplace, one must "encourage social distancing and enhance spacing between employees", "including through physical barriers, changing layout of workspaces, encouraging telework"..."when and where feasible" [2]. The CDC defined Social distancing, as "keeping space between yourself and other people outside of your home", and recommended to "stay at least 6 feet (about 2 arms' length) from other people"... "even when wearing a face covering", to not gather in groups and to "stay out of crowded places" [3].

Thus, in our own neonatal intensive care unit (NICU), morning or evening report can be a daunting task if one wants to comply with the CDC guidelines. These handovers customarily involve the patient, at least two residents (the one finishing and the one starting a shift), the attending physician, the bedside nurse, and at times also a Neonatology fellow, a nurse practitioner, a respiratory therapist, a social worker, a dietitian, one or both parents of the child, together with other medical or paramedical consultants and students. This number of participants is incompatible with CDC requirements in most average size patient rooms and in many conference rooms designed well before the Covid-19 pandemics, at times when social distancing was nearly unheard of.

We therefore followed the CDC recommendation of the use of IT technology [3] in order to enable bedside handover, while most participants may sit in their own office or in a

Netanel Wasserteil

netanelw@szmc.org.il

1 Department of Neonatology, Shaare Zedek Medical Center, Jerusalem, Israel

2 Sackler Faculty of Medicine, Tel Aviv University, Tel Aviv, Israel meeting room while practicing social distancing. We would like here to share our experience with it.

1. Handover is performed with a minimum of participants, that is, two residents and one attending, together with the bedside nurse and one of the parents of the infant. All other participants are located in a different meeting room or even in their respective offices.

2. The resident who finishes his shift hands over the patients with the Zoom application [4]. For reasons of information security, the Zoom software cannot be installed on our hospital computers, and is only used on laptops that are not connected to the medical information software or the Hospital's network. Importantly, the Zoom software prevents non-invited guests from joining the meeting. All participants must be individually allowed to the meeting by the meeting organizer. Thus, access to confidential medical information is prevented from uninvited guests. The handing over physician pushes a cart equipped with a Zoom-downloaded laptop computer. The cart carries an additional computer connected by Wi-Fi to the electronic medical records of the patients, two external speakers and an external mobile camera. The camera is wired to the laptop. It may be moved as needed during the session in order to focus on the baby, or on a specific part of equipment, such as cardiorespiratory monitor, ventilator screen, or cerebral function monitor. A short movie depicting the equipment and the way it is used can be accessed at the YouTube address: https://youtu.be/elzkvEptNEQ.

3. For participants located in a meeting room, we use a laptop computer connected to a large screen that also includes speakers (via HDMI (high-definition multimedia interface) connection) as well as an ambient microphone. Thus, participants that sit far from the laptop may ask questions, express opinions, or suggest changes in management. An additional meeting room computer linked to the hospital 
Electronic records allows participants to the medical file of the patients, including nursing reports, results of lab tests, imaging, and so on.

4. Other participants not present physically in the meeting room (for instance, sitting in their own office) may connect to the handover Zoom session on their own personal smartphones after joining the meeting address provided to them minutes before the handover session. Importantly, the Zoom software includes a split screen that allows all participants to see each other whenever they speak.

5. All participants, wherever located, are required to respect CDC distancing rules in the site where they are located.

We have been using these means of communication during handover sessions over the past weeks to the unanimous satisfaction of our 9 neonatologists and 80 nurses, as well as that of our infection control team.

Author contributions YK contributed to the concept and its realization, and reviewed critically the manuscript. $\mathrm{ABN}$ contributed to the realization of the project and to trouble shooting of technical issues, and reviewed critically the manuscript. FBM contributed to the concept and the writing of the manuscript. NW contributed to the concept and its realization, and to the writing of the manuscript. All authors reviewed the manuscript for important intellectual contents and approved the final version. All authors agree to be accountable for all aspects of the work.

\section{Compliance with ethical standards}

Conflict of interest The authors declare that they have no conflict of interest.

Publisher's note Springer Nature remains neutral with regard to jurisdictional claims in published maps and institutional affiliations.

\section{References}

1. Smeulers M, Lucas C, Vermeulen H. Effectiveness of different nursing handover styles for ensuring continuity of information in hospitalised patients. Cochrane Database Syst Rev. 2014;CD009979. https://doi.org/10.1002/14651858.CD009979.pub2.

2. CDC. Workplace decision tool. https://www.cdc.gov/coronavirus/ 2019-ncov/community/organizations/workplace-decision-tool.html (2019). Accessed 22 May 2020.

3. CDC. Social distancing. https://www.cdc.gov/coronavirus/2019ncov/prevent-getting-sick/social-distancing.html (2019). Accessed 22 May 2020.

4. Zoom Video Communications. https://en.wikipedia.org/wiki/Zoom_ Video_Communications. Accessed 2 Jun 2020. 